\title{
Newborn care practices and its determinants among postnatal mothers in Dessie Referral Hospital, Northeast Ethiopia
}

\author{
Yaregal Semanew ${ }^{1}$, Meaza Etaye ${ }^{1}$, Alemayehu Tizazu ${ }^{1}$, Desalegn Abebaw ${ }^{1}$ and Tsegaye Gebremedhin ${ }^{2 *}$
}

\begin{abstract}
Objective: Newborn care practices like the initiation of breastfeeding within an hour, delay baby bathing, cord cutting with a safe instrument, and thermal care is a crucial intervention for the avoidance of more than $75 \%$ of neonatal deaths. Therefore, this study aimed to describe the practices and determinants of newborn care among postnatal mothers attending postnatal clinics in Dessie Referral Hospital, Northeast Ethiopia.

Results: A total of 418 postnatal mothers included in the study. The finding indicated that the proportion of initiation of breastfeeding within an hour, baby bathing after $24 \mathrm{~h}$, cord cutting with a safe instrument, and thermal care was $83.9 \%, 75.8 \%, 46.9 \%$, and $80.8 \%$ respectively. Overall, $46.9 \%(95 \% \mathrm{Cl} 41.9,51.9)$ of newborn care practices was good. In the multivariable logistic regression analysis; women earning 651-1400 Ethiopian birr monthly ( $\mathrm{AOR}=0.428 ; 95 \% \mathrm{Cl}$ $0.183,0.999)$, women who delivered spontaneous vaginally for their recent delivery ( $\mathrm{AOR}=0.438 ; 95 \% \mathrm{Cl} 0.240,0.800)$, and mothers who had antenatal follow up once $(A O R=0.111 ; 95 \% \mathrm{Cl} 0.013,0.944)$ were factors significantly associated with newborn care practices. Therefore, enhancing antenatal care services and providing counseling for these spontaneously delivered mothers will increase newborn care practices.
\end{abstract}

Keywords: Practice, Newborn care, Postnatal mothers, Ethiopia

\section{Introduction}

Many countries in Sub-Saharan Africa are reported to have made little or no progress towards the child survival target, and some countries had even witnessed a deterioration in child survival rates [1]. Fifty-two percent of neonatal deaths are due to lack of appropriate care given to neonates, and most of those deaths could be prevented through low-cost interventions like quality care at birth and essential newborn care practices [2]. To save the life of neonates, the recommended WHO essential newborn care practices are crucial interventions; which includes clean cord care, thermal protection, early and exclusive breastfeeding, delay bathing, care for the low birth weight newborn and management of newborns [3].

\footnotetext{
*Correspondence: tsegishg27@gmail.com

2 Department of Health Systems and Policy, University of Gondar, P.O. Box: 196, Gondar, Ethiopia

Full list of author information is available at the end of the article
}

In Ethiopia, suboptimal newborn care practices still persist and neonatal mortality rates have been resistant to change and contributes about $43 \%$ of all under-five deaths $[4,5]$.

The first 28 days of life is the most vulnerable time for a child's survival with an average global rate of 18 deaths per 1000 live births (LBs) in 2017 [6]. More than 90\% of neonatal deaths occur in sub-Saharan Africa (27 deaths per 1000 LBs in 2017) and about half of the deaths occur at home [7].

Ethiopia reported having made little or no progress towards the child survival target which is majorly contributed by neonatal mortality. The neonatal mortality rate (NMR) and postneonatal mortality rate were 29 and 19 deaths per 1000 LBs respectively with the proportions of early $79 \%$ and late neonatal deaths $21 \%$ [8].

The lack of progress in the reduction of NMR may be explained by the high proportion of birth taking place at home, low availability and poor newborn care practices [9-11]. There are also numerous unscientific and 
unhygienic health practices and social taboos in neonatal care that makes the newborn extremely vulnerable [12].

The first $48 \mathrm{~h}$ after delivery is the time when the mother and baby are most vulnerable to morbidity and mortality associated with childbirth $[13,14]$.

It is estimated that $75 \%$ of neonatal deaths could be avoided with simple, low-cost tools that already exist such as sterile blades to cut the umbilical cord, using clean dry clothes to wrap and keep babies warm, and early initiation of breastfeeding.

A study conducted in Mandura District Northwest Ethiopia shows; $48.1 \%$ of mothers began breastfeeding within the first hour of birth and $37.8 \%$ bathed their baby after $24 \mathrm{~h}$ of birth [9]. A study conducted in four regions of Ethiopia shows bathing during the first $24 \mathrm{~h}$ of life (74.7\%), application of butter and other substances to the cord (19.9\%), and discarding of colostrum milk (44.5\%) [10].

Even though there are some studies assessing newborn care practices in Ethiopia, there was no study done in Dessie Referral Hospital, which is the only referral public Hospital that serves for many populations in Northeast Ethiopia. The main aim was to describe the practices and determinants of newborn care among postnatal mothers attending postnatal clinics of Dessie Referral Hospital.

\section{Main text \\ Methods \\ Study design and setting}

A facility-based cross-sectional study was conducted to describe the newborn care practices and determinants among postnatal mothers attending postnatal clinics in Dessie referral Hospital from April 13 to May 18, 2018. Dessie Referral Hospital is found in Dessie town, South Wollo Zone $401 \mathrm{~km}$ to the Northeast of Addis Ababa, Ethiopia.

The study populations were all selected postnatal mothers who came for postnatal services in postnatal clinics of Dessie referral Hospital during the data collection period. Postnatal mothers with an alive newborn within 42 days after delivery were included, whereas postnatal mothers who were unconscious, seriously ill and mentally retarded were excluded.

\section{Sample size and sampling procedures}

The sample size was determined using Epi-Info version 7.1 statistical software; using a proportion of mothers having good newborn care practice $50 \%$ to get the maximum sample size with a $5 \%$ margin of error. Finally, adding a $10 \%$ non-response rate the final sample was 423 . Systematic random sampling was used with the sampling fraction $K^{\text {th }}$ was calculated $(k=N / n=865 / 423=2)(973$ mothers have visited the hospital for postnatal service in April 2017 from health management information system report) and the first case was selected by lottery method. Newborn care practice is the dependent variable, whereas sociodemographic and economic factors, parity, history of ANC, place of delivery, mode of delivery, and knowledge of mothers about newborn care were the independent variables. An interviewer-administered structured questioner was first prepared in English, and then translated into the local language (Amharic), and then back to English to maintain consistency. A pretest was conducted on $5 \%$ of the sample at Boru-Meda Hospital and then the necessary correction was made. Training was given to both the data collectors and supervisors, and supervisors monitored the data collection process on a daily basis.

\section{Measurements}

Initiation of breastfeeding: the recommended practice of breastfeeding a newborn baby initiated breastfeeding within $1 \mathrm{~h}$ after birth.

Baby bathing: the practice of newborn baby bathing only after $24 \mathrm{~h}$ of birth.

Cord cutting: the practice of cutting a cord with a new blade or a boiled blade.

Thermal care: when the newborn was dried and wrapped after birth.

Finally, newborn care practice is dichotomized based on the four newborn care practices mentioned above. Those mothers provided three or more practices were categorized as "good newborn care practices" otherwise they categorized as "poor newborn care practices" $[9,10]$.

\section{Data management and analysis}

Data were entered to Epi-Data Version 3.1 and exported to SPSS version 22 for analysis. Factors were tested using the bivariable analysis, and $p$-value $\leq 0.2$ was a candidate for the multivariable logistics regression analysis. Adjusted odds ratio (AOR) with a 95\% CI and p-value $<0.05$ was used in multivariable logistic regression analysis to show the association between explanatory and dependent variables.

\section{Results}

Sociodemographic and economic characteristics of study participants

A total of 418 postnatal mothers responded to the interviewer-administered questionnaire with $98.8 \%$ response rate. Of these, 361 (86.4\%) were between the age of 21 and 35 years and $236(56.5 \%)$ were multiparous. Moreover, $294(70.3 \%)$ of them were a housewife and $387(92.6 \%)$ were married. Religiously, 255 (61.0\%) were Muslim and 
Table 1 Sociodemographic and economic characteristics of postnatal mothers at Dessie Referral Hospital, April $2018(n=418)$

\begin{tabular}{|c|c|c|c|}
\hline Variables & Category & Frequency & Percent (\%) \\
\hline \multirow[t]{3}{*}{ Age in years } & $15-20$ & 13 & 3.1 \\
\hline & $21-35$ & 361 & 86.4 \\
\hline & $36-49$ & 44 & 10.5 \\
\hline \multirow[t]{4}{*}{ Marital status } & Single & 11 & 2.6 \\
\hline & Married & 387 & 92.6 \\
\hline & Divorced & 12 & 2.9 \\
\hline & Widowed & 8 & 1.9 \\
\hline \multirow[t]{4}{*}{ Religion } & Orthodox & 133 & 31.8 \\
\hline & Muslim & 255 & 61.0 \\
\hline & Protestant & 17 & 4.1 \\
\hline & Catholic & 13 & 3.1 \\
\hline \multirow[t]{2}{*}{ Ethnicity } & Amhara & 402 & 96.2 \\
\hline & Oromo & 16 & 3.8 \\
\hline \multirow[t]{5}{*}{ Educational status } & $\begin{array}{l}\text { Unable to read and } \\
\text { write }\end{array}$ & 57 & 13.6 \\
\hline & Able to read and write & 37 & 8.9 \\
\hline & Primary education & 172 & 41.1 \\
\hline & Secondary education & 91 & 21.8 \\
\hline & College and above & 61 & 14.6 \\
\hline \multirow[t]{5}{*}{ Occupation } & Housewife & 294 & 70.3 \\
\hline & Private employee & 28 & 6.7 \\
\hline & $\begin{array}{l}\text { Government } \\
\text { employee }\end{array}$ & 42 & 10.0 \\
\hline & Merchant & 42 & 10.0 \\
\hline & Student & 12 & 3.0 \\
\hline \multirow{3}{*}{$\begin{array}{l}\text { Average monthly } \\
\text { income of family } \\
\text { (ETB) }\end{array}$} & $151-650$ ETB & 11 & 2.6 \\
\hline & 651-1400 ETB & 31 & 7.4 \\
\hline & $>1401$ ETB & 376 & 90.0 \\
\hline
\end{tabular}

ETB Ethiopian Birr

$90.0 \%$ of the respondents had a monthly income of more than 1401 Ethiopian Birr (Table 1).

\section{Antenatal care and delivery history of study participants}

Majority 407 (97.4\%) of respondents had ANC follow up at least once. Among these, 295 (72.4\%) were started ANC follow up before their 4th months of gestation and 241 (59.2\%) of them had visited ANC four times and above. Whereas, 398 (95.2\%) have received TT vaccination. Of the total respondents, 411 (98.3\%) of postnatal mothers delivered at a health facility and attended by a skilled healthcare provider; whereas, the rest delivered at home. Regarding their mode of delivery; $57.1 \%, 24.9 \%$, and $18.0 \%$ of mothers delivered spontaneously, by cesarean section and instrumentally respectively.

Two hundred thirteen $(52.3 \%)$ of postnatal mothers did not get information about newborn care during their
ANC visits and the remaining; 141 (34.6\%), 47 (11.6\%) and $6(1.5 \%)$ postnatal mothers got information about breastfeeding, immunization, and thermoregulation respectively. Of these, for 161 (83.0\%) mothers the information was provided by a nurse and for 33 (17.0\%) mothers by a doctor (Additional file 1: Table S1).

\section{Postnatal mothers' newborn care practices}

Majority 286 (68.4\%) of mothers placed their baby on the abdomen before the placenta was delivered and 196 (46.9\%) of mothers used a new blade to cut the cord after delivery. After the cord was cut, 234 (56.0\%) of mothers cover with cloth and 110 (26.3\%) of mothers uncover and keep dry. Additionally, 10 (2.4\%) of mothers apply anything (butter and vaseline) on the stump after the baby's' cord was cut. Moreover, 338 (80.8\%) of mothers wrapped the baby with a new cloth immediately to keep their baby warm and 406 (97.1\%) of mothers initiate breastfeeding immediately after delivery. Of these, 141 (33.7\%) of mothers initiated before $30 \mathrm{~min}$ and 210 (50.2\%) between $30 \mathrm{~min}$ and an hour.

Furthermore, 364 (87.1\%) of postnatal mothers cleaned their breast and hands before breastfeeding their baby and 257 (61.5\%) of mothers fed their baby 8-12 times per day. Additionally, 317 (75.8\%) of mothers bath their baby after 1 day of their delivery and only 97 (23.2\%) of mothers immunized their baby at birth. Among these home deliveries majority (71.4\%) of mothers practicing newborn care poorly/sub-optimally. But, from those facility born babies, only $47.3 \%$ received newborn care optimally. Overall, 222 (53.1\% CI 48.1, 58.1) of postnatal mothers' newborn care practice was poor (Table 2).

\section{Determinants of newborn care practices among postnatal mothers}

In the multivariable analysis, women earn 651-1400 Ethiopian birr monthly were $57.2 \%$ less likely to practice newborn care than women who earn more than 1400 $(\mathrm{AOR}=0.428 ; 95 \%$ CI 0.183, 0.999). Women who delivered spontaneously vaginally for their recent delivery were $56.2 \%$ less likely practicing newborn care for their baby as compared to women who had instrumental delivery $(\mathrm{AOR}=0.438 ; 95 \%$ CI $0.240,0.800)$. Regarding the history of antenatal care; these mothers who had antenatal follow up once were $88.9 \%$ less likely providing newborn care services as compared to these mothers who had four and more antenatal follow up $(\mathrm{AOR}=0.111$; 95\% CI 0.013, 0.944) (Table 3).

\section{Discussion}

Our finding revealed that $46.9 \%$ (95\% CI 41.9, 51.9) of postnatal mothers' newborn care practices was good. This finding is higher than a study conducted in 
Table 2 Newborn care practice of postnatal mothers at Dessie referral Hospital, Northeast Ethiopia, 2018

\begin{tabular}{|c|c|c|c|}
\hline Variables & Category & Frequency & Percent (\%) \\
\hline \multirow[t]{3}{*}{ Where was the baby placed before the placenta was delivered? } & On the mother's abdomen & 286 & 68.4 \\
\hline & On clean surface & 128 & 30.6 \\
\hline & Other & 4 & 1.0 \\
\hline \multirow[t]{4}{*}{ What instrument was used to cut the cord after delivery? } & New or boiled blade & 196 & 46.9 \\
\hline & Old and un boiled blade & 6 & 1.4 \\
\hline & Don't know & 214 & 51.2 \\
\hline & Other $^{a}$ & 2 & 0.5 \\
\hline \multirow[t]{3}{*}{ What did you do to the umbilical stump after the cord is cut? $(n=418)$} & Cover with cloth & 234 & 56.0 \\
\hline & Uncover, keep dry and clean & 110 & 26.3 \\
\hline & I do not know & 74 & 17.7 \\
\hline \multirow[t]{2}{*}{ Did anybody apply anything on the stump after the baby's cord was cut? } & Yes & 10 & 2.4 \\
\hline & No & 408 & 97.6 \\
\hline \multirow[t]{2}{*}{ If yes, what was applied? $(n=10)$} & Butter & 2 & 20.0 \\
\hline & Vaseline & 8 & 80.0 \\
\hline \multirow{3}{*}{ What did you do to keep your baby warm? $(n=418)$} & Skin to skin contact & 75 & 18.0 \\
\hline & Wrapped the baby in a cloth immediately & 338 & 80.8 \\
\hline & Both & 5 & 1.2 \\
\hline \multirow[t]{4}{*}{ What was the first feed you gave to the baby immediately after delivery? } & Breast milk & 406 & 97.1 \\
\hline & Cow milk & 4 & 1.0 \\
\hline & Formula feed & 2 & 0.5 \\
\hline & Other ${ }^{b}$ & 6 & 1.4 \\
\hline \multirow[t]{3}{*}{ When did you start breastfeeding after delivery?) } & Immediately & 141 & 33.7 \\
\hline & $30 \mathrm{~min}$ to $1 \mathrm{~h}$ & 210 & 50.3 \\
\hline & Other & 67 & 16.0 \\
\hline \multirow[t]{2}{*}{ Do you clean your breast and hands before breastfeeding the baby? $(n=418)$} & Yes & 364 & 87.1 \\
\hline & No & 54 & 12.9 \\
\hline \multirow[t]{3}{*}{ How often did you breastfeed your baby in a day? } & $8-12$ times & 257 & 61.5 \\
\hline & On-demand & 158 & 37.8 \\
\hline & Don't breastfeed & 3 & 0.7 \\
\hline \multirow[t]{4}{*}{ When did you start bathing your baby after birth? } & Immediately after birth & 9 & 2.1 \\
\hline & After $6 \mathrm{~h}$ of birth & 24 & 5.8 \\
\hline & After 1 day of birth & 317 & 75.8 \\
\hline & Other $^{c}$ & 68 & 16.3 \\
\hline \multirow[t]{2}{*}{ Was your baby immunized at birth? } & Yes & 97 & 23.2 \\
\hline & No & 321 & 76.8 \\
\hline \multirow[t]{2}{*}{ Overall newborn care practice } & Good & 196 & 46.9 \\
\hline & Poor & 222 & 53.1 \\
\hline
\end{tabular}

a Scissors and locally available materials

b Water, butter

c After 5 days, 7 days and did not remember

Mandura and Damot pulasa Woreda; the newborn care practice among postnatal mothers was $40.6 \%$ and $24 \%$ respectively $[9,13]$. This might be due to the difference in study setting; facility based includes those who have good health-seeking behavior and knowledge about newborn care which increases newborn care practices. This finding is higher than a study conducted in Awobel district; revealed that the level of newborn care practices among postnatal mothers was $23.1 \%$ [15]. The possible explanation might be the socio-economic difference and Dessie is more urbanized as compared to other districts.

Our finding shows that prevalence of initiation of breastfeeding within an hour, baby bathing after $24 \mathrm{~h}$, cord cutting and thermal care was $83.9 \%, 75.8 \%, 46.9 \%$, and $80.8 \%$ respectively. This finding is similar with a study conducted in Rural Pondicherry, India; 70.6\% of postnatal mothers' bath their baby after 1 day and 
Table 3 Bivariable and multivariable logistic analysis showed factors associated with poor newborn care practice among postnatal mothers at Dessie Referral Hospital, Northeast Ethiopia, 2018

\begin{tabular}{|c|c|c|c|c|c|c|}
\hline \multirow[t]{2}{*}{ Factors } & \multirow[t]{2}{*}{ Category } & \multicolumn{2}{|c|}{$\begin{array}{l}\text { Newborn care } \\
\text { practice }\end{array}$} & \multirow[t]{2}{*}{ COR $(95 \% \mathrm{Cl})$} & \multirow[t]{2}{*}{ AOR $(95 \% \mathrm{Cl})$} & \multirow[t]{2}{*}{ p-value } \\
\hline & & Good & Poor & & & \\
\hline \multirow[t]{3}{*}{ Age in years } & $15-20$ & 6 & 7 & $10.00(1.195,83.691)$ & $4.228(0.414,43.185)$ & 0.224 \\
\hline & $21-35$ & 175 & 186 & $0.886(0.473,1.660)$ & $0.861(0.417,1.778)$ & 0.686 \\
\hline & $36-49$ & 20 & 24 & 1 & 1 & \\
\hline \multirow[t]{5}{*}{ Educational status } & Unable to read and write & 22 & 35 & $1.875(0.900,3.904)$ & $1.868(0.828,4.213)$ & 0.132 \\
\hline & Able to read and write & 21 & 16 & $0.898(0.394,2.044)$ & $0.681(0.267,1.736)$ & 0.421 \\
\hline & Primary education & 70 & 102 & $1.717(0.954,3.093)$ & $1.643(0.873,3.091)$ & 0.123 \\
\hline & Secondary education & 50 & 41 & $0.966(0.504,1.854)$ & $0.995(0.497,0.992)$ & 0.988 \\
\hline & College and above & 33 & 28 & 1 & 1 & \\
\hline \multirow[t]{3}{*}{ Monthly income } & $151-650$ ETB & 5 & 6 & $1.001(0.300,3.337)$ & $0.672(0.158,2.868)$ & 0.592 \\
\hline & $651-1400$ ETB & 20 & 11 & $0.459(0.214,0.984)$ & $0.428(0.183,0.999)$ & $0.050^{*}$ \\
\hline & $>1401$ ETB & 171 & 205 & 1 & 1 & \\
\hline \multirow[t]{2}{*}{ First ANC visit } & Before 4 months & 150 & 154 & 1 & 1 & \\
\hline & Four and above months & 42 & 61 & $1.415(0.900,2.225)$ & $0.981(0.579,1.663)$ & 0.944 \\
\hline \multirow[t]{2}{*}{ Knew about thermal care } & Yes & 146 & 147 & 1 & 1 & \\
\hline & No & 50 & 75 & $1.490(0.974,2.278)$ & $1.225(0.763,1.967)$ & 0.400 \\
\hline \multirow{2}{*}{$\begin{array}{l}\text { Knew about the initiation of } \\
\text { breastfeeding }\end{array}$} & Yes & 192 & 209 & 1 & 1 & \\
\hline & No & 4 & 13 & $2.986(0.957,9.314)$ & $1.437(0.352,5.864)$ & 0.613 \\
\hline \multirow[t]{3}{*}{ Mode of delivery } & SVD & 130 & 109 & $0.419(0.243,0.722)$ & $0.438(0.240,0.800)$ & $0.007^{*}$ \\
\hline & Cesarean section & 41 & 63 & $0.768(0.413,1.429)$ & $0.912(0.467,1.784)$ & 0.789 \\
\hline & Instrumental & 25 & 50 & 1 & 1 & \\
\hline \multirow[t]{4}{*}{ Number of ANC visit } & One & 143 & 136 & $0.106(0.013,0.845)$ & $0.111(0.013,0.944)$ & $0.044^{*}$ \\
\hline & Two & 35 & 42 & $0.133(0.016,1.104)$ & $0.151(0.017,1.314)$ & 0.087 \\
\hline & Three & 13 & 28 & $0.239(0.027,2.092)$ & $0.245(0.026,2.298)$ & 0.218 \\
\hline & Four and above & 3 & 7 & 1 & 1 & \\
\hline
\end{tabular}

$A O R$ adjusted odd ratio, $C l$ confidence interval, COR crude odd ratio, ETB Ethiopian Birr, EBF exclusive breastfeeding, SVD spontaneous vaginal delivery, ANC antenatal care

* Significant at $\mathrm{p}$-value $<0.05$

$84.8 \%$ of mothers gave thermal care [14] but, higher than a study conducted in Kenya [16]. Moreover, initiation of breastfeeding within an hour is higher than a study conducted in Awobel (41.6\%) and Damot Pulasa Woreda $(45.8 \%)[13,15]$. The prevalence of safe cord cutting in our study is much lower than a study finding in Awobel district (97.6\%) [15].

In this study; monthly income, number of ANC visit and mode of delivery were factors associated with newborn care practices among postnatal mothers. Mothers who earn a monthly income of 651-1400 Ethiopian birr were $57.2 \%$ less likely to practice newborn care than women who earn more than 1400 Ethiopian birr and women who delivered spontaneously vaginally for their recent delivery were $56.2 \%$ less likely practicing newborn care as compared to women who had instrumental delivery. This is similar to a study conducted in eastern Uganda shows mothers in the upper quintile provide more practices to their newborns than their counterparts [17].

Moreover, mothers who had a history of antenatal follow up once were $88.9 \%$ less likely providing newborn care services as compared to those mothers who had four and more. This finding was consistent with a study done in Mandura district, Uganda, Tanzania, and Jimma $[9,17-19]$. This might be due to the possibility of getting information about the components and importance of newborn care practice from healthcare providers during ANC.

\section{Conclusion and recommendation}

This study indicated that the majority of newborn care practices are sub-optimal dominantly for home born babies. Monthly income of the respondents, antenatal care follow-up and mode of delivery were determinants for newborn care practices. 
Policy makers and healthcare providers shall consider the provision of newborn care practices to prevent neonatal death especially within the first $24 \mathrm{~h}$ and do more on rising practices of newborn care majorly for those home born babies.

\section{Limitations}

The major limitation of this study was facility based which affect the magnitude of newborn care practice among postnatal mothers in the community. Another limitation of this study was respondents' bias that aims to respond to all the recommended newborn cares.

\section{Additional file}

Additional file 1: Table S1. Antenatal care and delivery history of postnatal mothers at Dessie Referral Hospital, Northeast Ethiopia, 2018.

\section{Abbreviations}

ANC: antenatal care; AOR: adjusted odds ratio; $\mathrm{Cl}$ : confidence interval; $\mathrm{COR}$ : crude odds ratio; NMR: neonatal mortality rate; PNC: postnatal care; SPSS: statistical package for social science; SVD: spontaneous vaginal delivery; TT: tetanus toxoid; WHO: World Health Organization.

\section{Authors' contributions}

YS, ME and AT conceived the study, developed the tool, coordinated the data collection activity, and carried out the statistical analysis. DA and TG participated in the design of the study and development of the tool, performed statistical analysis and drafted the manuscript. All authors read and approved the final manuscript.

\section{Author details}

${ }^{1}$ Department of Pediatrics and Child Health Nursing, Wollo University, Dessie, Ethiopia. ${ }^{2}$ Department of Health Systems and Policy, University of Gondar, P.O. Box: 196, Gondar, Ethiopia.

\section{Acknowledgements}

Authors would like to thank all respondents for their willingness to participate in the study. We are also grateful to Dessie Referral Hospital, and Wollo University, Department of Pediatrics and Child Health Nursing staff for their technical support. Finally, our appreciation goes to data collectors for their unreserved contribution in data collection activities.

\section{Competing interests}

The authors declare that they have no competing interests.

\section{Availability of data and materials}

Data will be available upon reasonable request from the corresponding author.

\section{Consent for publication \\ Not applicable.}

\section{Ethics approval and consent to participate}

Ethical approval was obtained from the Wollo University Ethical Review Committee after approving the procedure (References Number PCHN/43/2018). Permission letter was also obtained from Dessie Referral Hospital. Respondents were briefed about the purpose and objectives of the study. Participant's privacy and confidentiality of the information were maintained through nonidentifiers of the name. Verbal consent was obtained from each participant and from their parents/guardians for those had difficulty to communicate to ensure their voluntariness to participate in the study after explaining the procedures, risks, and benefits of a study. Moreover, all participants had a right to withdraw at any time or to skip for a single question or segment of questions.
Funding

This study was funded by self (Principal investigator).

\section{Publisher's Note}

Springer Nature remains neutral with regard to jurisdictional claims in published maps and institutional affiliations.

Received: 22 December 2018 Accepted: 15 February 2019

Published online: 21 February 2019

\section{References}

1. Countdown Coverage Writing Group, Countdown to 2015 Core Group, Bryce J, Daelmans B, Dwivedi A, Fauveau V, Lawn JE, Mason E, Newby H, Shankar A, et al. Countdown to 2015 for maternal, newborn, and child survival: the 2008 report on tracking coverage of interventions. Lancet. 2008:371:1247-58.

2. Lawn JE, Blencowe H, Oza S, You D, Lee AC, Waiswa P, et al. Every newborn: progress, priorities, and potential beyond survival. Lancet. 2014;384(9938):189-205.

3. WHO. WHO recommendations on home-based records for maternal, newborn and child health. Geneva: World Health Organization; 2018.

4. Darmstadt GL, Bhutta ZA, Cousens S, Adam T, Walker N, De Bernis L, et al. Evidence-based, cost-effective interventions: how many newborn babies can we save? Lancet. 2005;365(9463):977-88.

5. Central Statistical Agency Addis Ababa E. Ethiopian demographic and health survey 2016.

6. UNICEF. Levels and trends in child mortality; estimates developed by the UN inter-agency group for child mortality estimation. New York: UNICEF; 2017.

7. UNICEF. Levels and trends in child mortality report; estimates developed by the UN inter-agency group for child mortality estimation. New York: UNICEF; 2018.

8. Central Statistical Agency Addis Ababa E. Ethiopian Demographic and Health Survey 2011.

9. Tegene T, Andargie G, Nega A, Yimam K. Newborn care practice and associated factors among mothers who gave birth within one year in Mandura District. Northwest Ethiopia. Clin Mother Child Health. 2015;12:172. https://doi.org/10.4172/2090-7214.1000172.

10. Callaghan-Koru JA, Seifu A, Tholandi M, de Graft-Johnson J, Daniel E, Rawlins B, et al. Newborn care practices at home and in health facilities in 4 regions of Ethiopia. BMC Pediatr. 2013;13(1):198.

11. Mekonnen W, Desalegn A. Quality of service and associated factors in neonatal intensive care unit at Debre Berhan referral hospital, Debre Berhan Ethiopia: a cross-sectional study. Med J. 2018;11(5):412.

12. Kumola AM. Newborn care practices among postnatal mothers in Garissa county, Kenya. 2015.

13. Chichiabellu TY, Mekonnen B, Astawesegn FH, Demissie BW, Anjulo AA. Essential newborn care practices and associated factors among home delivered mothers in Damot pulasa Woreda, southern Ethiopia. Reprod Health. 2018;15(1):162.

14. Vijayalakshmi S, Patil R, Datta S. Community-based study on newborn care practices and its determinants in rural Pondicherry, India. J Neonatal Biol. 2014;3(5):1-5. https://doi.org/10.4172/2167-0897.1000158.

15. Kokebie T. Community based essential newborn care practices and associated factors among women in the rural community of Awabel district. Int J Adv Sci Res. 2015;1 (1):17-27.

16. Kumola AM. Newborn care practices among postnatal mothers in Garissa county, Kenya. 2010.

17. Waiswa P, Peterson S, Tomson G, Pariyo GW. Poor newborn care practices - a population based survey in eastern Uganda. BMC Pregnancy Childbirth. 2010;10(1):9.

18. Penfold S, Hill Z, Mrisho M, Manzi F, Tanner M, Mshinda H, et al. Newborn care practices in southern Tanzania. PLoS ONE. 2010;5(12):e15593.

19. Girma T. Traditional newborn care in Jimma town, southwest Ethiopia. Ethiop J Health Sci. 2008;18(3). 